\title{
Water-assisted oxygen activation during selective oxidation reactions
}

\author{
Hung-Vu Tran ${ }^{1}$, Hieu A. Doan ${ }^{1}$, Bert D. Chandler ${ }^{2}$ and Lars C. Grabow ${ }^{1, *}$
}

Abstract:

The selective functionalization of hydrocarbons with oxygen to produce valuable commodity chemicals is inherently challenging, because of the thermodynamic stability of the complete combustion products. Emerging green synthesis routes and sustainable energy production also rely on the success of selective oxidation reactions. As one of the unselective by-products, water is always present under reaction conditions and numerous studies indicate that catalytic activity and selectivity of selective oxidation reactions may be tuned by judiciously controlling the water content during the reaction. Some experimentally verified examples include the preferential oxidation of carbon monoxide, direct hydrogen peroxide synthesis, propene epoxidation and alcohol oxidation. Finally, it has been predicted that the direct conversion of methane to methanol can benefit from the right amount of water near the active site during oxygen activation.

\section{Address}

${ }^{1}$ Department of Chemical and Biomolecular Engineering, University of Houston, Houston, TX 77204, USA

2 Department of Chemistry, Trinity University, San Antonio, TX 78212, USA

Corresponding author: *Grabow, Lars C. (grabow@uh.edu)

Keywords: partial oxidation; selective oxidation; water; oxygen activation; heterogeneous catalysis 


\section{Introduction}

Numerous recent studies have eluded to the phenomenon that the presence of water $\left(\mathrm{H}_{2} \mathrm{O}\right)$ in quantities ranging from a few ppm to aqueous solutions can significantly increase reaction rates and, more importantly, the selectivity for certain partial oxidation reactions. This effect is observed in both homogenously [1,2] and heterogeneously [3-5] catalyzed reactions. While water may affect catalytic reactions in multiple ways, its ability to shuttle protons to and from reactants, intermediates and products can directly change the course of a reaction. In aqueous, homogeneous environments the facile proton transfer is known as the Grotthuss mechanism and is rather well understood [6,7]. In contrast, the co-catalytic effect of water in heterogeneously catalyzed reactions has only recently started to attract attention. In 2012, for example, Merte et al. used a combination of high-speed, high-resolution scanning tunneling microscopy, isotope-exchange experiments and density functional theory (DFT) calculations to identify a novel water-mediated proton diffusion mechanism on a FeO/Pt(111) surface at low temperatures [8]. The participation of a water molecule during proton hopping allows the formation of an $\mathrm{H}_{3} \mathrm{O}^{+}$-like transition state, which lowers the activation energy barrier from 1.02 $\mathrm{eV}$ to only $0.21 \mathrm{eV}$, equivalent to a 16 -fold increase in the diffusion rate at room temperature. A more recent ab initio molecular dynamics study provides evidence for a Grotthuss-like, watermediated mechanism for fast and long-range proton diffusion at the $\mathrm{Pt} / \mathrm{CeO}_{2}$ interface [9].

Partial oxidation reactions are universally challenged by the relative thermodynamic instability of the desired products compared to the total oxidation products (water and carbon dioxide, $\mathrm{CO}_{2}$ ) [10]. Further, partial oxidations are typically exothermic, providing the necessary energy to for deeper oxidation reactions. Thus, successful examples of difficult direct selective oxidations are rare. Notable progress has been made using non-traditional oxidants and/or noble metal catalysts at low to moderate temperatures. In particular, soft oxidants, e.g. sulfur [11,12], or noble metals such as gold, silver, or copper in combination with hydrogen peroxide $\left(\mathrm{H}_{2} \mathrm{O}_{2}\right)$ or nitrous oxide $\left(\mathrm{N}_{2} \mathrm{O}\right)$ seem promising [10]. The strong oxidizing power of $\mathrm{H}_{2} \mathrm{O}_{2}$ along with its environmentally friendly product (water) make it a noteworthy alternative oxidant. It also reacts more readily on noble metals, which are less suited to catalyze the direct dissociation of molecular oxygen $\left(\mathrm{O}_{2}\right)$ shown in Scheme $1(\mathrm{a}) . \mathrm{H}_{2} \mathrm{O}_{2}$ is currently produced in the multistep anthraquinone process, which requires the use of mixtures of organic solvents and liquid extraction steps. Thus, the production and abatement of harmful by-products increases synthesis costs and results in a negative environmental impact [13]. Attempts are underway to develop green $\mathrm{H}_{2} \mathrm{O}_{2}$ synthesis routes directly from $\mathrm{O}_{2}$ and $\mathrm{H}_{2}[14,15]$, but safety concerns from handling and transporting $\mathrm{H}_{2} \mathrm{O}_{2}$ or potentially explosive mixtures of $\mathrm{H}_{2}$ and $\mathrm{O}_{2}$ remain. 


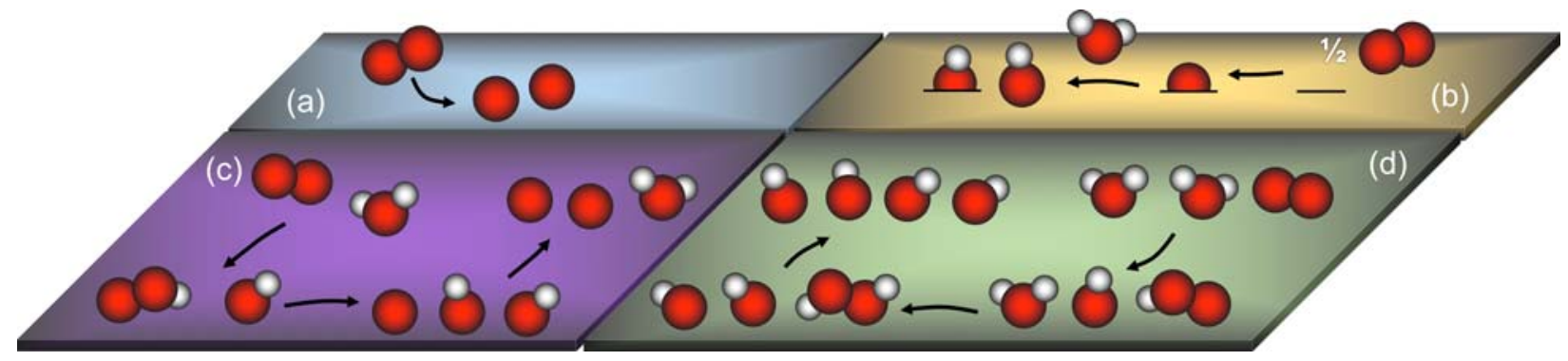

Scheme 1. Formation of active oxygen intermediates: (a) $\mathrm{O}_{2}$ dissociation; (b) hydroxyl formation with a pre-existing $\mathrm{O}$ atom (in the common case of metal-oxides, the pre-existing $\mathrm{O}$ atom is a lattice oxygen); (c) water-assisted $\mathrm{O}_{2}$ dissociation; and (d) $\mathrm{O}_{2}$ activation with excess water.

The reaction intermediates derived from $\mathrm{H}_{2} \mathrm{O}_{2}$ as an oxidant are generally considered to be surface bound hydroperoxyl $(\mathrm{OOH})$ and hydroxyl $(\mathrm{OH})$, both of which can also be produced from $\mathrm{H}_{2} \mathrm{O}$ and $\mathrm{O}_{2}$ via the proton exchange sequences illustrated in Scheme 1(c),(d). Water and oxygen are environmentally benign, suggesting that sustainable synthesis routes for challenging selective oxidation reactions exist. In this context, we provide a concise review of notable accomplishments since 2012 on heterogeneously catalyzed selective oxidation reactions that use water as a co-catalyst to activate oxygen via proton transfer steps. In the interest of brevity we limit this review to (preferential) carbon monoxide (CO) oxidation, propylene epoxidation, alcohol oxidation, and methane partial oxidation; we note many other examples also exist [1625]. For homogenously catalyzed processes, particularly where water affects the transition state stability, we refer interested readers to previous reviews $[1,5,26]$.

\section{Selective oxidations involving carbon monoxide (CO) and hydrogen $\left(\mathrm{H}_{2}\right)$}

With applications in vehicle-exhaust emission control, $\mathrm{CO}_{2}$ lasers and sensors, and $\mathrm{H}_{2}$ production and purification for proton-exchange-membrane (PEM) fuel cells and ammonia synthesis, transition metal catalyzed $\mathrm{CO}$ oxidation $\left(\mathrm{CO}+1 / 2 \mathrm{O}_{2} \rightarrow \mathrm{CO}_{2}\right)$ is of substantial interest [27-30]. CO oxidation is routinely used as the prototypical model reaction in heterogeneous catalysis research because it is seemingly simple, yet exhibits a variety of complex phenomena $[27,28,31]$. Highlights include Ertl's observation of temporal oscillations and spatial pattern formation on Pt(110) [27], Goodman's work on bridging the pressure gap on Pt-group metals [32], and Haruta's breakthrough discovery that nanoparticulate gold is highly active for $\mathrm{CO}$ oxidation even below room temperature [33,34]. This discovery undoubtedly marks the beginning of the "gold rush" in heterogeneous catalysis leading to an astonishing > 5000 papers published since 1987 and summarized in several review articles [34-39]. The bulk of the early studies concerns the dependence of catalytic activity on the Au nanoparticle size, the effect of various metal oxide support types, and more generally the nature of the active site, while the presence of moisture and its benefits for $\mathrm{CO}$ oxidation activity has been the topic of more recent studies $[3,4,34]$. The effect of moisture is in fact remarkable; co-feeding small amounts of water as little as $200 \mathrm{ppm}$ leads to a larger than 10-fold increase in $\mathrm{CO}$ oxidation activity of $\mathrm{Au} / \mathrm{SiO}_{2}$ at $0{ }^{\circ} \mathrm{C}$. [40]. Proposed roles of water during $\mathrm{CO}$ oxidation on $\mathrm{Au}$ can be categorized as: (i) 
creation of cationic gold atoms as active sites; (ii) transformation and decomposition of stable carbonate intermediates blocking reaction sites; (iii) direct participation in $\mathrm{CO}_{2}$ formation; and (iv) activation of oxygen [4]. Roles (i)-(iii) are specific to $\mathrm{CO}$ oxidation on Au, but phenomenon (iv), oxygen activation, is common to aerobic oxidations over numerous types of catalysts. We therefore concentrate on the role of water in oxygen activation during $\mathrm{CO}$ oxidation, and note that other factors specific to each reaction system also exist. We also highlight that water's direct participation as a co-catalyst in $\mathrm{CO}_{2}$ formation is distinct from the water-gas shift (WGS) reaction. In WGS catalysis, water is a reactant, regenerating surface hydroxyl groups, which react with $\mathrm{CO}$.

Strict differentiation between the effect of water and the catalyst support is elusive. Unless studied under well-controlled, ultra high vacuum (UHV) conditions, metal-oxides generally form surface hydroxyl groups (s-OH) according to Scheme 1(b). These support hydroxyls may react directly with $\mathrm{CO}$ to form the carboxyl $(\mathrm{COOH})$ intermediate [39]. Daniells et al. used a high temperature pre-treatment for $\mathrm{Au} / \mathrm{Fe}_{2} \mathrm{O}_{3}$ catalysts to remove support hydroxyls as water, finding that $\mathrm{CO}$ oxidation activity was drastically reduced for the dehydroxylated material [41]. Surface dehydration was confirmed by water detection during temperature programmed desorption (TPD). Consequently, Bond and Thompson proposed that water promotes $\mathrm{CO}$ oxidation by maintaining the concentration of reactive $\mathrm{s}-\mathrm{OH}$ groups from the reaction of water with the metal oxide support [39]. Lattice oxygen atoms removed as $\mathrm{CO}_{2}$ are ultimately replaced by $\mathrm{O}_{2}$ in a Mars-van-Krevelen type mechanism. Although the direct involvement of s-OH and lattice oxygen atoms has been frequently suggested, carefully conducted isotope labeling experiments demonstrate that lattice oxygen is not a reactive oxygen source and that observed oxygen exchange is due to secondary scrambling effects $[22,42]$.

Water-assisted activation of $\mathrm{O}_{2}$ to form a reactive $\mathrm{OOH}$ intermediate, shown in Scheme 1(c), has also been invoked to explain gold's oxidation activity [22,43]. In fact, many conflicting interpretations can be reconciled by the $\mathrm{Au} / \mathrm{TiO}_{2} \mathrm{CO}$ oxidation mechanism illustrated in Figure 1 [16]. Using in situ infrared spectroscopy to quantify the amount of s-OH groups and molecularly adsorbed water, a strong correlation between weakly bound surface water and the reaction rate was found. Furthermore, a H/D kinetic isotope effect (KIE) of nearly 2 was measured, indicating that a proton transfer step is involved in the rate-determining step of the reaction. Complimentary DFT calculations suggested that s-OH groups at the $\mathrm{Au} / \mathrm{TiO}_{2}$ interface are necessary to anchor water molecules near Au via hydrogen bonding. These water molecules can then serve as proton source to form the reactive $\mathrm{Au}-\mathrm{OOH}$ species in a barrier free proton transfer step to adsorbing $\mathrm{O}_{2}$. The Au-OOH intermediate subsequently reacts with Au-CO to generate an $\mathrm{Au}-\mathrm{COOH}$ intermediate. Notably, the $\mathrm{O}-\mathrm{OH}$ bond cleavage in the presence of Au$\mathrm{CO}$ requires an activation barrier of only $0.1 \mathrm{eV}$, thereby constituting one of the lowest reported energy pathways for $\mathrm{O}_{2}$ activation. The $\mathrm{KIE}$ was attributed to the rate-determining second proton transfer from Au-COOH back to the adsorbed water layer, which is necessary to release $\mathrm{CO}_{2}$ and close the catalytic cycle. The barrier for this step decreases further when additional water molecules are present, consistent with the experimentally observed equilibrium isotope effect under very wet conditions [22]. 
Figure 1

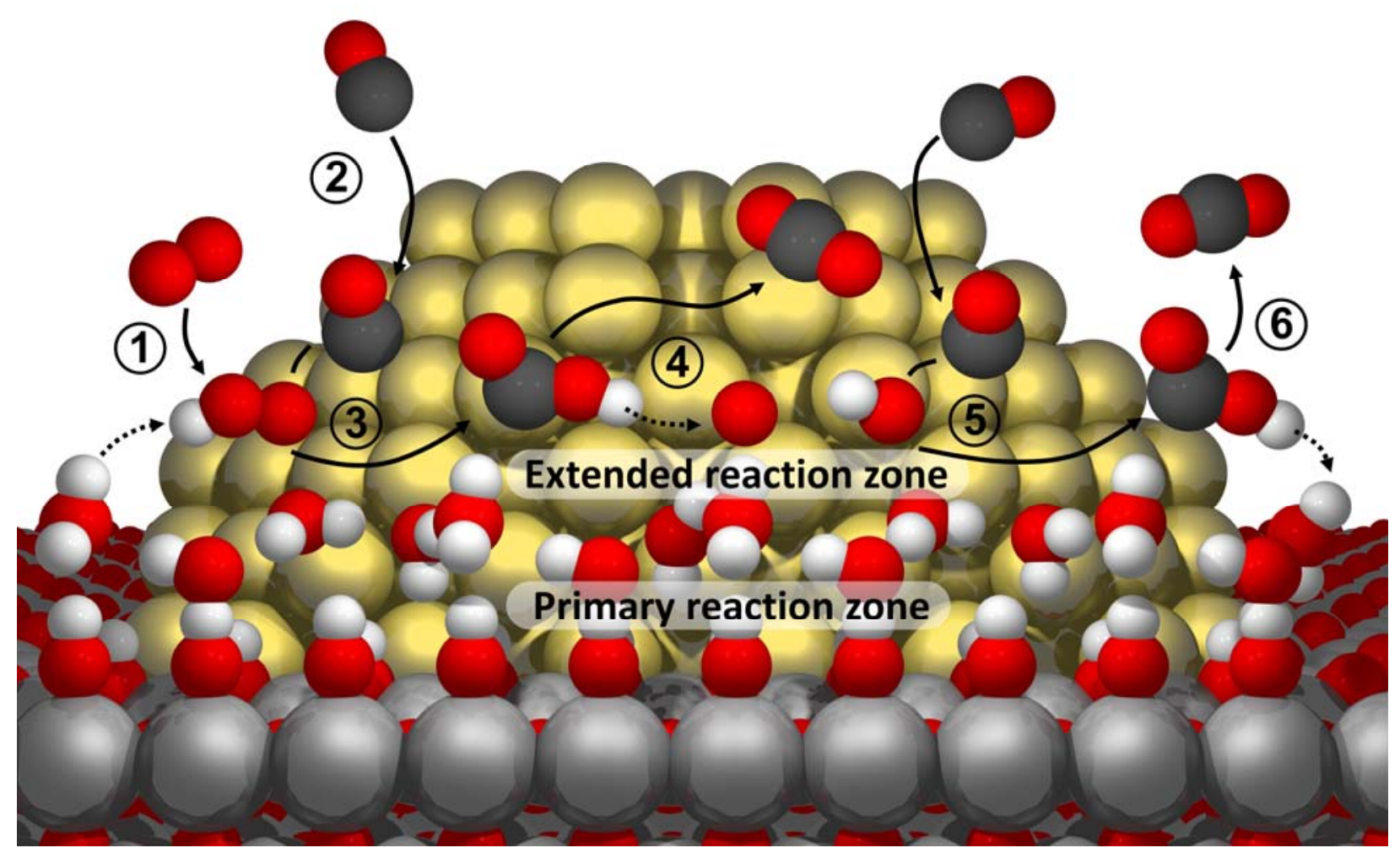

Figure 1. Proposed mechanism for water-assisted $\mathrm{CO}$ oxidation over $\mathrm{Au} / \mathrm{TiO}_{2}$. The reaction steps are (1) $\mathrm{s}-\mathrm{H}_{2} \mathrm{O}+\mathrm{O}_{2}+\mathrm{Au} \rightarrow \mathrm{Au}-\mathrm{OOH}+\mathrm{s}-\mathrm{OH}$; (2) $\mathrm{CO}+\mathrm{Au} \rightarrow \mathrm{Au}-\mathrm{CO}$; (3) $\mathrm{Au}-\mathrm{CO}+\mathrm{Au}-$ $\mathrm{OOH} \rightarrow \mathrm{Au}-\mathrm{COOH}+\mathrm{Au}-\mathrm{O}$; (4) $\mathrm{Au}-\mathrm{COOH}+\mathrm{Au}-\mathrm{O} \rightarrow \mathrm{CO}_{2}+\mathrm{Au}-\mathrm{OH}+\mathrm{Au}$; (5) Au-CO + Au-OH $\rightarrow$ $\mathrm{Au}-\mathrm{COOH}+\mathrm{Au}$; and (6) $\mathrm{Au}-\mathrm{COOH}+\mathrm{s}-\mathrm{OH} \rightarrow \mathrm{CO}_{2}+\mathrm{Au}+\mathrm{s}-\mathrm{H}_{2} \mathrm{O}$. From reference [16]. Reprinted with permission from AAAS.

Based on the newly established water-assisted mechanism [16], record-breaking improvements to the preferential oxidation (PROX) of $\mathrm{CO}$ with $\mathrm{O}_{2}$ in an $\mathrm{H}_{2}$-rich environment have been reported [17]. Rather than designing a new catalyst, a commercial $\mathrm{Au} / \mathrm{Al}_{2} \mathrm{O}_{3}$ catalyst and optimized feed water content achieved unprecedented $\mathrm{CO}$ conversion and $\mathrm{O}_{2}$-to- $\mathrm{CO}_{2}$ selectivity. Under optimal conditions, CO slip could be reduced to below 10 ppm, while maintaining 80-90 $\% \mathrm{O}_{2}$-to- $\mathrm{CO}_{2}$ selectivity. The surface water concentration on the $\mathrm{Al}_{2} \mathrm{O}_{3}$ support under these conditions was quantified to be ca. 1-2 monolayers, and is nearly identical to the optimal support water coverage for $\mathrm{CO}$ oxidation on $\mathrm{Au} / \mathrm{TiO}_{2}$ [16]. The high selectivity for $\mathrm{CO}$ oxidation over $\mathrm{H}_{2}$ oxidation was in part attributed to the increased $\mathrm{CO}$ oxidation rate, but also to the blockage of $\mathrm{H}_{2}$ dissociation sites near the $\mathrm{Au} / \mathrm{Al}_{2} \mathrm{O}_{3}$ interface by water. This is an exceptional example of how fundamental mechanistic insight can pave the road for major scientific advances with direct relevance to industrially important processes.

Similar water-assisted $\mathrm{CO}$ oxidation mechanisms have not only been proposed for Au, but also for Ag [18], and Pt [22,44] catalysts. Sheu and Chang used DFT to study CO oxidation on the 
water the pre-covered $\mathrm{Ag}(111)$ surface, proposing the formation of $\mathrm{OOH}$ according to Scheme 1(c) [18]. The remainder of the proposed mechanism shares many steps with the mechanism depicted in Figure 1, including the rate-determining decomposition of $\mathrm{COOH}$ by proton transfer to $\mathrm{OH}$ to form $\mathrm{CO}_{2}$ to regenerate the $\mathrm{H}_{2} \mathrm{O}$ co-catalyst. The two mechanisms differ in the reaction step between $\mathrm{OOH}$ and $\mathrm{CO}$ forming either $\mathrm{COOH}+\mathrm{O}$ [16] or $\mathrm{CO}_{2}+\mathrm{OH}$ [18] as products.

The promotional effect of water on $\mathrm{O}_{2}$ activation is not limited to noble metals, on which $\mathrm{O}_{2}$ activation is inherently difficult. An exhaustive mechanistic study by Iglesia and co-workers showed that $\mathrm{O}_{2}$ pre-activation to $\mathrm{OOH}$ via a proton transfer from $\mathrm{H}_{2} \mathrm{O}$ on $\mathrm{Pt} / \mathrm{Al}_{2} \mathrm{O}_{3}$ catalyst also accelerates the rate of $\mathrm{CO}$ oxidation [22]. Changing from dry to wet conditions ( $0 \mathrm{kPa}$ to $0.5 \mathrm{kPa}$ of $\mathrm{H}_{2} \mathrm{O}$ ) causes the rate per surface atom to increase from 0.08 to $0.28 \mathrm{~mol} \mathrm{~s}^{-1} \mathrm{~g}$-at $\mathrm{Pt}_{\mathrm{s}}{ }^{-1}$. For comparison, the equivalent rate increase over $\mathrm{Au} / \mathrm{Al}_{2} \mathrm{O}_{3}\left(0.08\right.$ to $\left.2.55 \mathrm{~mol} \mathrm{~s} \mathrm{~g}^{-1} \mathrm{gt} \mathrm{Au}_{\mathrm{s}}{ }^{-1}\right)$ is much larger. Although $\mathrm{CO}$ oxidation over $\mathrm{Pt}$ and $\mathrm{Au}$ is limited by the ability to activate $\mathrm{O}_{2}$, the difference in sensitivity to the water coverage speaks to the existence of different reasons for difficult $\mathrm{O}_{2}$ activation. Unlike $\mathrm{Au}, \mathrm{Pt}$ is capable of dissociating $\mathrm{O}_{2}$, but its strong affinity to CO leads to high $\mathrm{CO}$ coverage and surface poisoning. While the presence of $\mathrm{H}_{2} \mathrm{O}$ may lower the $\mathrm{CO}$ surface coverage, it can also decrease the barrier for $\mathrm{O}_{2}$ dissociation on the remaining vacant sites, and in turn leading to higher $\mathrm{CO}$ oxidation rates. Indeed, the lower activation pathway for $\mathrm{O}_{2}$ activation via the $\mathrm{OOH}$ intermediate is reflected in an $18 \mathrm{~kJ} / \mathrm{mol}$ lower apparent activation energy in the presence of $\mathrm{H}_{2} \mathrm{O}$. In contrast, Au is not inhibited by high $\mathrm{CO}$ coverage and water is involved in both $\mathrm{O}_{2}$ binding and $\mathrm{COOH}$ decomposition; thus, the promotional effect of water on $\mathrm{O}_{2}$ activation is more pronounced.

In contrast to the discussion thus far, complete $\mathrm{O}-\mathrm{O}$ bond activation is undesired when it comes to direct $\mathrm{H}_{2} \mathrm{O}_{2}$ synthesis. Nevertheless, Wilson and Flaherty have demonstrated that high proton concentrations result in improved selectivity and turnover frequency for $\mathrm{H}_{2} \mathrm{O}_{2}$ production over $\mathrm{Pd} / \mathrm{SiO}_{2}$ catalysts in protic solvents (water and methanol) [15]. A thorough kinetic analysis explained this in terms of a competition between $\mathrm{OOH}$ dissociation and further protonation to yield $\mathrm{H}_{2} \mathrm{O}_{2}$. This difference is also captured in Scheme $1(\mathrm{~d})$, in which the abundance of protons (here shown to originate from $\mathrm{H}_{2} \mathrm{O}$ ) favors the rapid formation of $\mathrm{H}_{2} \mathrm{O}_{2}$ prior to the formation of $\mathrm{OH}$. As Wilson and Flaherty alluded, secondary $\mathrm{O}-\mathrm{O}$ bond scission in $\mathrm{H}_{2} \mathrm{O}_{2}$ may be reduced when larger Pd particles with a higher fraction of coordinated $\mathrm{Pd}$ atoms are used.

\section{Propylene epoxidation}

Propylene oxide (PO) is one of the most important commodity chemicals with more than 7 million tons annual worldwide market capacity [34]. Polyurethane, polyether polyols, glycol ethers, and propylene glycols are just a few of the various compounds produced from PO [45]. Analogous to ethylene epoxidation over silver catalysts, the ideal process for $\mathrm{PO}$ production is the selective epoxidation of propylene with molecular $\mathrm{O}_{2}: \mathrm{C}_{3} \mathrm{H}_{6}+1 / 2 \mathrm{O}_{2} \rightarrow \mathrm{C}_{3} \mathrm{H}_{6} \mathrm{O}[46,47]$. This goal, however, has not yet been achieved and is considered by some as a Holy Grail in catalysis [34]. Current industrial PO production requires the use of chlorohydrin, organic hydroperoxides, or hydrogen peroxide in the so-called hydrogen peroxide to propylene oxide (HPPO) process [48]. While each process has its own advantages, they either require toxic, corrosive, expensive to transport reagents, or produce harmful by-products, whose separation, 
abatement or recycling adds to the overall process cost [34]. Progress towards safer and sustainable PO production may be achieved by eliminating hydrogen peroxide in the HPPO process through in-situ generation of the right oxygen-containing intermediates. With $\mathrm{Au} / \mathrm{TiO}_{2}$ being known as selective catalyst for direct $\mathrm{H}_{2} \mathrm{O}_{2}$ synthesis from a mixture of $\mathrm{O}_{2} / \mathrm{H}_{2}$, Haruta et al. confirmed the feasibility of in-situ $\mathrm{H}_{2} \mathrm{O}_{2}$ generation on gold nanoparticles deposited on Ticontaining supports for the selective epoxidation of propylene [34,45,49]. Although these results are promising, the primary remaining barriers are poor hydrogen efficiency due to hydrogen oxidation to water, and the potential explosion risk when working with $\mathrm{H}_{2} / \mathrm{O}_{2}$ mixtures.

Active oxidants derived from $\mathrm{H}_{2} \mathrm{O}_{2}$ are likely surface-bound $\mathrm{OOH}$ and $\mathrm{OH}$, which can also be generated from mixture of $\mathrm{O}_{2}$ and $\mathrm{H}_{2} \mathrm{O}$ (Scheme 1(c),(d)). Thus, it is reasonable to expect that controlled amounts of added water can assist during $\mathrm{O}_{2}$ activation, forming the oxygencontaining surface intermediates required for selective propylene epoxidation with $\mathrm{O}_{2}$. Consequently, the research groups of Iglesia, Haruta, and Vajda have independently pursued this idea on various supported gold catalysts [50-52]. Ojeda and Iglesia [50] used $\mathrm{TiO}_{2}$ supported Au nanoclusters ( $3.3 \mathrm{~nm})$ and reported up to $70 \% \mathrm{PO}$ selectivity. Haruta and coworkers found that $50 \%$ PO selectivity could be achieved over 1.0-2.0 nm small Au clusters supported on alkaline-treated titanosilicalite-1 (TS-1) [51,53]. Even smaller particles, i.e. Au6-10 clusters with diameters below $1.0 \mathrm{~nm}$, supported on three monolayer thin films of $\mathrm{Al}_{2} \mathrm{O}_{3}$ grown by atomic layer deposition (ALD) were used by Vajda and co-workers, resulting in up to $90 \%$ PO selectivity [52]. The selectivity to $P O$ in all three studies drops drastically when water was removed from the feed; in the absence of water, PO production was no longer observed. It is evident from these experiments that water plays a vital role in promoting the desired epoxidation reaction.

Figure 2 provides a generic reaction scheme for supported Au propylene epoxidation catalysts. Selective PO production is attributed to the reaction of propylene with either $\mathrm{Au}-\mathrm{OOH}$ or $\mathrm{s}-\mathrm{OOH}$, both of which are formed by water-assisted (proton transfer) $\mathrm{O}_{2}$ activation (Scheme 1(c)). In the case of TS-1 as support a correlation between the variation in the UV/Vis band characteristic for $\mathrm{Ti}-\mathrm{OOH}$ and the production of $\mathrm{PO}$ is consistent with $\mathrm{Ti}-\mathrm{OOH}$ as the active oxygen intermediate [51]. The same conclusion was reached in a kinetic study by Perez Fernandez et al. [25]. Both groups agree that Au-O species are responsible for the formation of the undesired products $\mathrm{CO}_{2}$ and acrolein. 
Figure 2

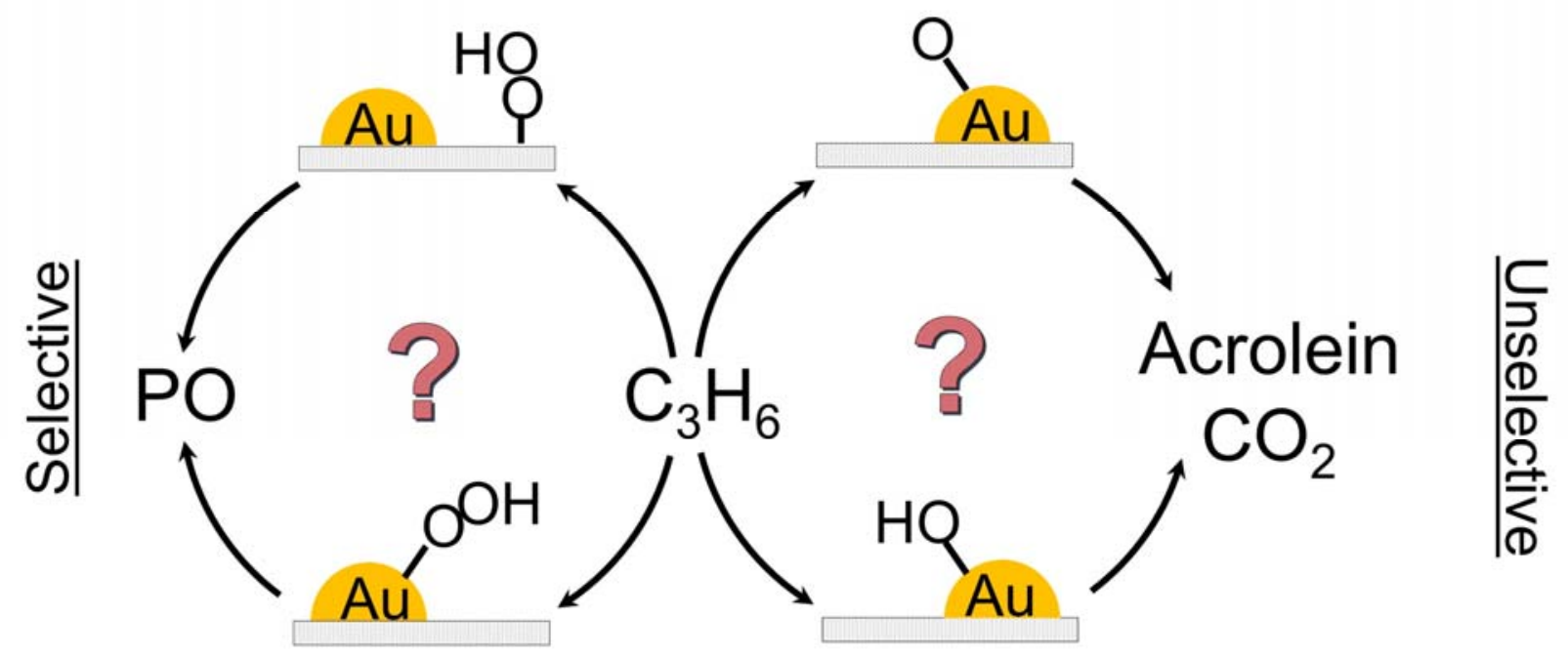

Figure 2. The role various oxygen containing reaction intermediates derived from $\mathrm{O}_{2} / \mathrm{H}_{2} \mathrm{O}$ in the selective epoxidation of propylene.

Theoretical studies are largely congruent with the water-assisted mechanism shown in Figure 2. Yet, the computational results also indicate that the reaction is structure sensitive, and that water participates indirectly by changing the nanoparticle structure and stabilizes transition states by solvation effects. For unsupported Au cluster models of only 10 and 38 atoms, Li and co-workers calculated a barrier for proton transfer from water to co-adsorbed $\mathrm{O}_{2}$ of only $\sim 0.2 \mathrm{eV}$ [54]. The subsequent reaction between $\mathrm{Au}-\mathrm{OOH}$ and propylene to form $\mathrm{PO}$ requires a barrier of ca. $0.8 \mathrm{eV}$ for $\mathrm{Au}_{10}$ and $1.0 \mathrm{eV}$ for $\mathrm{Au}_{38}$. The same group used a combination of global minimum searches and $a b$ initio molecular dynamics and determined that initially upright $\mathrm{Au}_{7}$ clusters on fully hydroxylated $\alpha-\mathrm{Al}_{2} \mathrm{O}_{3}(0001)$ transform into flat geometries when hydroxyl groups are removed as water [19,52]. This structural reconstruction, however, does not affect the finding that $\mathrm{Au}-\mathrm{OOH}$ is the selective intermediate leading to epoxidation. The barrier for $\mathrm{Au}-\mathrm{OOH}$ formation via proton transfer from $\mathrm{s}-\mathrm{H}_{2} \mathrm{O}$ to $\mathrm{Au}-\mathrm{O}_{2}$ is sensitive to the amount of water present and is lowered from $0.34 \mathrm{eV}$ to $0.16 \mathrm{eV}$, when an additional $\mathrm{s}-\mathrm{H}_{2} \mathrm{O}$ molecule is included in the simulation. The disparate conclusion regarding the selective epoxidation species, $\mathrm{Au}-\mathrm{OOH}$ for $\mathrm{Au} / \mathrm{Al}_{2} \mathrm{O}_{3}$ vs. S-OOH for Au/TS-1, may be explained by the different support materials used.

Although a general consensus exists for $\mathrm{OOH}$, either in the form of $\mathrm{s}-\mathrm{OOH}$ or $\mathrm{Au}-\mathrm{OOH}$, leading to the desired epoxidation of propylene, the pathways leading to the non-selective side products $\mathrm{CO}_{2}$ and acrolein are still debated. Some attribute the formation of undesired products to the existence of $\mathrm{Au}-\mathrm{OH}$ [19], while others have suggested Au-O as the responsible surface species [25,51]. More research efforts will be necessary to fully elucidate the specific roles of Au-O and $\mathrm{Au}-\mathrm{OH}$ and to enable the design of catalysts with improved PO selectivity. 


\section{Alcohol oxidation}

The liquid phase aerobic, selective oxidation of alcohols to value-added products (e.g. aldehydes, ketones or carboxylic acids) over solid catalysts is an industrially desired process and was reviewed by Mallat and Baiker in 2004 [55]. Since then numerous studies have appeared discussing the mechanistic implications of water on the product selectivity using Aubased catalysts [56-60]. The theme of this review, combining selective noble metal catalysts with $\mathrm{O}_{2}$ activation by water-mediated proton transfer chemistry, was successfully followed by Davis and co-workers, who developed methods for the aqueous aerobic oxidation of glycerol to glyceric acid and other partial oxidation products over Au and Au-Pd alloy catalysts [61,62]. Additional insight into the reaction mechanism was obtained from kinetic ${ }^{18} \mathrm{O}_{2}$ and $\mathrm{H}_{2}{ }^{18} \mathrm{O}$ labeling experiments over $\mathrm{Au} / \mathrm{C}, \mathrm{Au} / \mathrm{TiO}_{2}, \mathrm{Pd} / \mathrm{C}$, and $\mathrm{Pt} / \mathrm{C}$ catalysts combined with $\mathrm{DFT}$ calculations in collaboration with Neurock's group [20]. Under high $\mathrm{pH}$ conditions $(\mathrm{pH}>13)$ the Au-based catalysts exhibited higher turnover frequencies (TOF) than the $\mathrm{Pd}$ and $\mathrm{Pt}$ catalysts under identical conditions. In the absence of added base, Au was inactive. Adsorbed $\mathrm{Au}-\mathrm{OH}$ and hydroxide ions $\left(\mathrm{OH}^{-}\right)$in solution were ultimately identified as active species (Figure 3). Isotope labeling and DFT models supported the authors conclusion that $\mathrm{O}_{2}$ is needed to regenerate Au$\mathrm{OH} / \mathrm{OH}^{-}$through the in-situ formation of hydrogen peroxide and its subsequent decomposition to $2 \mathrm{Au}-\mathrm{OH}$ groups. As the $\mathrm{O}_{2}$ activation pathway in Scheme 1(d) shows, it requires more water and an additional proton transfer step than the mechanism depicted in Scheme 1(c). Considering the water-rich environment in aqueous solution and the low calculated proton transfer barriers the mechanism in Scheme 1(d) is entirely plausible.

\section{Figure 3}

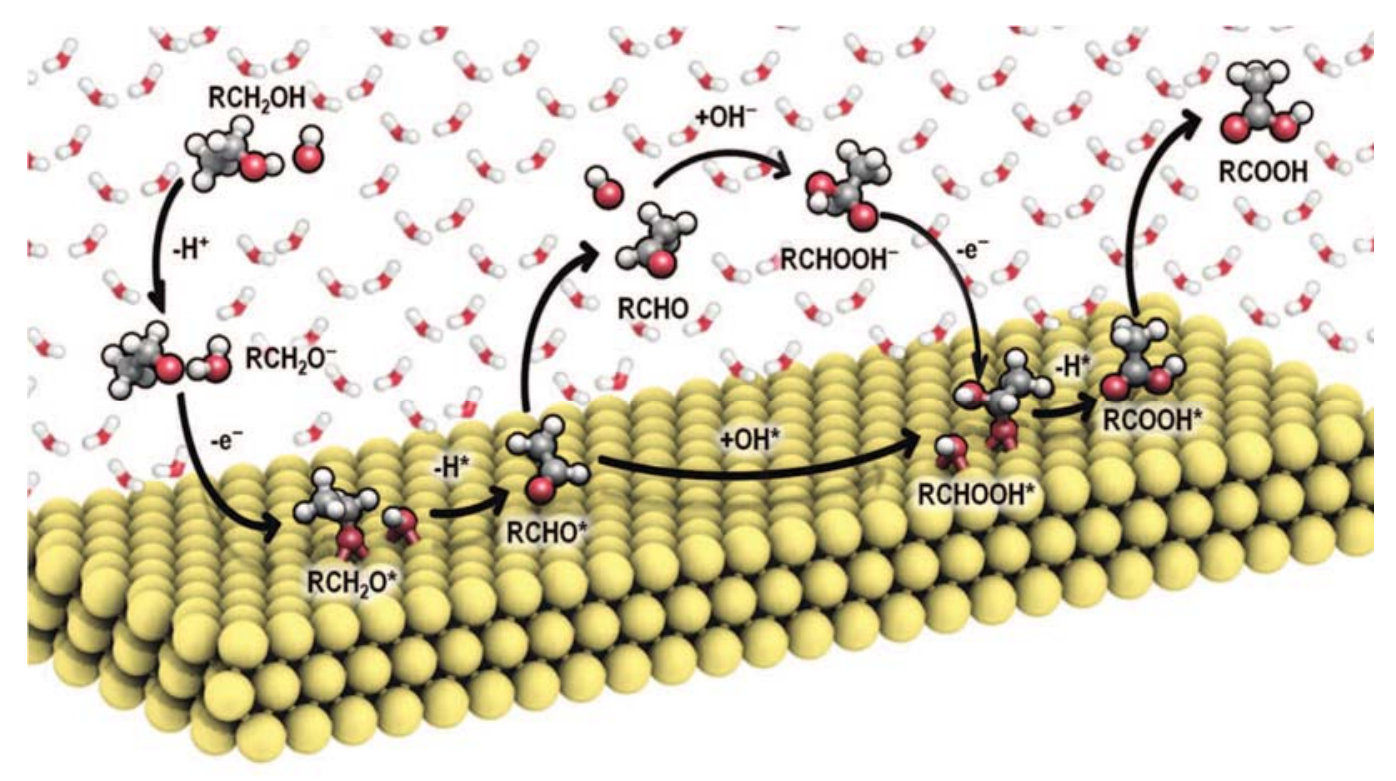

Figure 3. Reaction scheme for the oxidation of alcohols to acids over a Au surface in water at high $\mathrm{pH}$. Hydroxide facilitates elementary steps in alcohol oxidation in both the solution phase and at the metal/solution interface. From reference [20]. Reprinted with permission from AAAS. 
A variation of this mechanism has been proposed by Chang and co-workers based on their DFT work on methanol oxidation to formaldehyde on $\mathrm{Au}(111)$ surfaces [63]. The calculated barriers for $\mathrm{Au}-\mathrm{O}, \mathrm{Au}-\mathrm{OH}$ and $\mathrm{Au}-\mathrm{OOH}-m e d i a t e d$ methanol oxidation steps are all reasonably low, such that any of these surface intermediates are feasible oxidants. The endothermic formation of Au$\mathrm{OOH}$ via the steps shown in Scheme 1(c), however, was suggested as rate-determining step. This conclusion was drawn based on a calculated activation barrier of $0.91 \mathrm{eV}$ for the proton transfer from $\mathrm{H}_{2} \mathrm{O}$ to $\mathrm{O}_{2}$. In the presence of a second water molecule this barrier drops to 0.45 $\mathrm{eV}$, and $\mathrm{Au}-\mathrm{OOH}$ dissociation to $\mathrm{Au}-\mathrm{OH}$ and $\mathrm{Au}-\mathrm{O}$ turns into the most activated step with a barrier of $0.79 \mathrm{eV}$. The fact that Chang's group concluded that water-assisted $\mathrm{O}_{2}$ activation is rate limiting is likely a consequence of choosing bulk-like $\mathrm{Au}(111)$ as model surface. Thus, this finding is not necessarily in conflict with other studies; it rather manifests that Au-catalysis is strongly dependent on electronic and geometric factors, i.e. particle size, and support effects.

\section{Methane-to-methanol}

Despite decades of research the selective partial oxidation of methane-to-methanol remains one of the last frontiers in modern chemistry $[64,65]$. Inspired by nature's monooxygenase (MMO) enzyme, whose active site is composed of an Fe center in its soluble form (sMMO) and a Cu center in its particulate form (pMMO) [10], Hutchings' group studied Cu-promoted Fe/ZSM-5 and achieved three orders of magnitude higher methane-to-methanol activity than previously reported [21]. The caveat to this discovery is the need for hydrogen peroxide as oxidant. Nevertheless, research on $\mathrm{Fe}$ and $\mathrm{Cu}$ exchanged zeolites, primarily with MFI or MOR framework structure, has rapidly intensified in recent years [64-67]. Owing to its superior activity and selectivity, Cu/ZSM-5 with MFI structure has attracted great interest and its active site was identified as a mono( $\mu$-oxo) dicopper core, $[\mathrm{Cu}-\mathrm{O}-\mathrm{Cu}]^{2+}[68]$. Compared to the 10-membered ring channels in MFI, the MOR structure has larger 12-membered ring pores that allow stabilization of a trinuclear copper-oxo cluster [69]. The active site containing radical extraframework oxygen is generated from the Cu-exchanged zeolite sample by an appropriate oxygen treatment followed by exposure to methane to form methanol.

Water is regularly employed in methane-to-methanol studies on Cu-exchanged zeolites, but with the purpose to purge the zeolite framework and extract the strongly adsorbed methanol product. Indeed, DFT studies for Cu/MOR confirm that competitive water adsorption facilitates the release of methanol [70]. Yet, to date, no direct experimental evidence for water-assisted oxygen activation pathways during partial oxidation of methane on metal-exchanged zeolites has been reported. According to the DFT study by Yumura and co-workers, however, the presence of a single $\mathrm{H}_{2} \mathrm{O}$ molecule near the dicopper site in ZSM-5 enhances the activation of dioxygen via proton transfer analogous to Scheme 1 (c), whereas a second $\mathrm{H}_{2} \mathrm{O}$ molecule inhibits the reaction [23]. Given the ubiquitous presence of trace amounts of water in even ultra high purity gases, it is entirely plausible that this pathway contributes to the observed activity. 
Figure 4

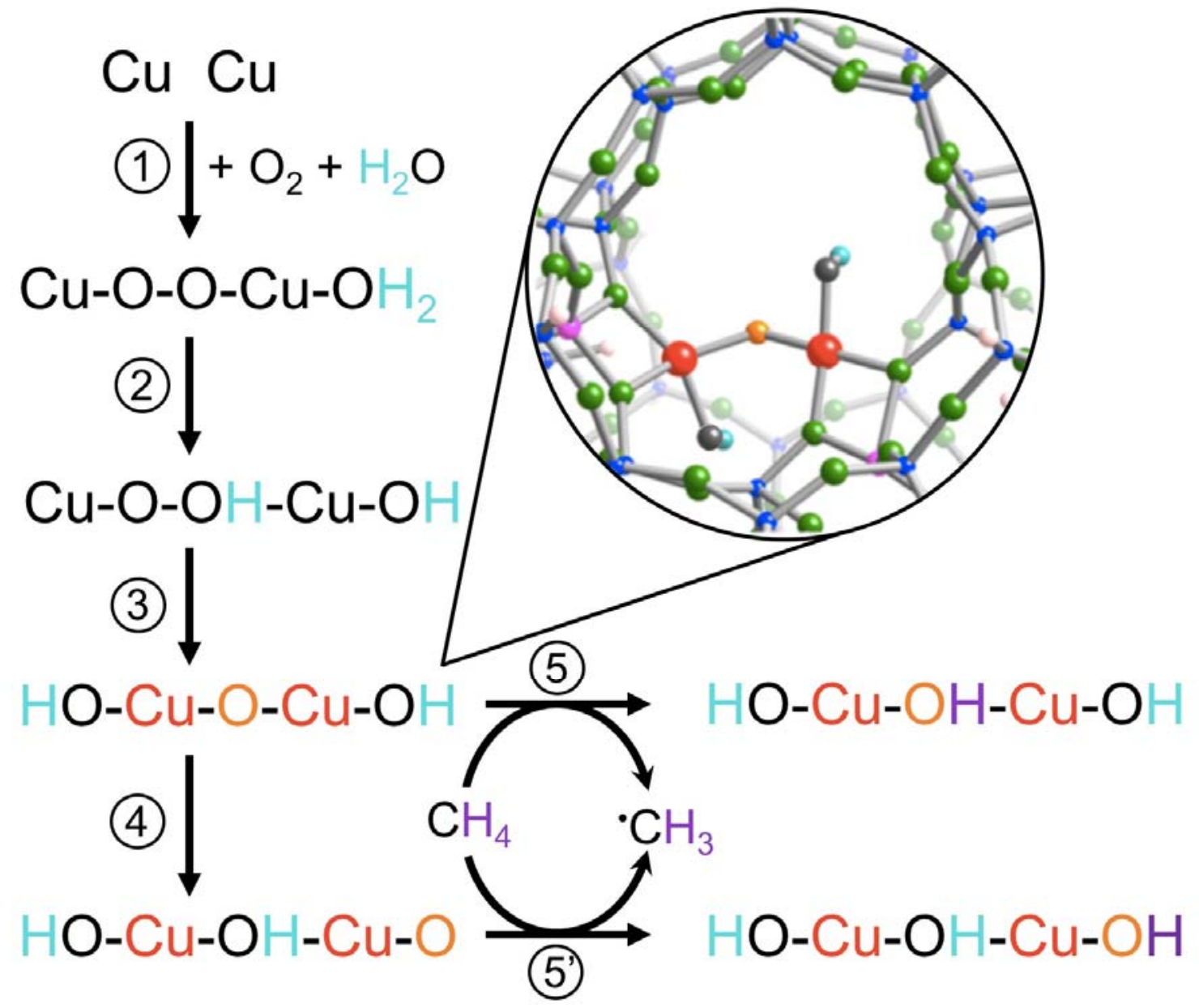

Figure 4. Predicted methane activation pathways over Cu/ZSM-5 catalyst assisted by water. Adapted from Reference [23].

The proposed water-mediated mechanism for methane activation over Cu/ZSM- 5 is illustrated in Figure 4 [23]. Adsorption of $\mathrm{O}_{2}$ and $\mathrm{H}_{2} \mathrm{O}$ to the dicopper site (step 1) forms the trans- $\mu-1,2-$ peroxo dicopper complex $\left(\mathrm{Cu}-\mathrm{O}-\mathrm{O}-\mathrm{Cu}-\mathrm{OH}_{2}\right)$. Next, one proton is transferred from adsorbed $\mathrm{H}_{2} \mathrm{O}$ to $\mathrm{O}_{2}$, generating the $\mathrm{Cu}-\mathrm{O}-\mathrm{OH}-\mathrm{Cu}-\mathrm{OH}$ intermediate (step 2, cf. Scheme 1(c)). The hydroperoxo $\mathrm{O}-\mathrm{OH}$ bond then breaks (step 3), forming the radical oxygen containing species $\mathrm{HO}-\mathrm{Cu}-\mathrm{O}-\mathrm{Cu}-\mathrm{OH}$ shown in the inset of Figure 4. An alternative radical oxygen containing isomer $\mathrm{HO}-\mathrm{Cu}-\mathrm{OH}-\mathrm{Cu}-\mathrm{O}$ can also be generated along step 4. Both of these radical oxygen complexes are capable of abstracting a $\mathrm{H} \bullet$ atom from methane, forming $\mathrm{CH}_{3}{ }^{*}$ (steps 5 and $5^{\prime}$ ). Similar radical oxygen containing complexes can be formed by the water-promoted $\mathrm{O}_{2}$ activation on Cu/ZSM-5 possessing a trinuclear copper core, indicating that the water-assisted mechanism may also apply to Cu/MOR and possibly other Cu-exchanged zeolites [23,69]. Further, these oxo-mediated radical abstraction processes are essentially the same types of mechanisms employed by MMO enzymes [10], which suggests that this may be a very general $\mathrm{C}-\mathrm{H}$ activation 
pathway. Verification of this theoretical prediction requires precise control of the water content inside the zeolite pore and may prove difficult, but the potential impact of a successful demonstration should provide sufficient motivation.

\section{Summary and Outlook}

In general, the use of noble metal catalysts, especially $\mathrm{Au}$, and mild to moderate reaction conditions favors partial oxidation products. In these catalytic systems $\mathrm{O}_{2}$ delivery can be controlled and selectivity is improved by avoiding overoxidation and complete combustion. The selectivity improvement often comes at the cost of low conversion causing overall process yields to remain below industry targets. A possible solution is a transition to more readily activated oxidizing agents, but these reactants are often costly, may have adverse environmental effects, and are typically more difficult to handle than $\mathrm{O}_{2}$.

Water-assisted $\mathrm{O}_{2}$ activation in mixtures of $\mathrm{O}_{2}$ and $\mathrm{H}_{2} \mathrm{O}$ is a new and promising approach to challenging partial oxidations. While the sequence of elementary steps varies for different catalysts and reaction conditions, there is general agreement that facile proton transfer steps between $\mathrm{H}_{2} \mathrm{O}$ and $\mathrm{O}_{2}$ leads to the formation of surface bound $\mathrm{OOH}, \mathrm{OH}$, and/or $\mathrm{O}$ species. These are the same surface intermediates as those derived from $\mathrm{H}_{2} \mathrm{O}_{2}$, implying that expensive $\mathrm{H}_{2} \mathrm{O}_{2}$ may ultimately be replaced by mixtures of $\mathrm{H}_{2} \mathrm{O}$ and $\mathrm{O}_{2}$ with minimal modifications to the catalyst. Moreover, the concentration and type of active oxygen species on the catalyst surface may be optimized through precise control of the amount of water (or protons) present during the reaction. Despite the reported benefits of water as co-catalyst care must be taken to avoid excess water conditions for systems in which $\mathrm{H}_{2} \mathrm{O}$ competitively adsorbs on reaction sites and thereby limits the adsorption of other reactants. An example of strong water inhibition is the oxidation of small alkanes on $\mathrm{PdO}$, where surface hydroxylation has been associated with catalyst deactivation [71].

We emphasize that water-assisted $\mathrm{O}_{2}$ activation is not only relevant to gold, on which $\mathrm{O}_{2}$ dissociation in the absence of water is difficult, but it also applies to Pt-group and other transition metal alloys for reactions in which $\mathrm{O}_{2}$ dissociation is rate-determining. It is important to note that even when water is not deliberately added, it can hardly be avoided as a by-product during partial oxidation reactions. Thus, the water-mediated activation of $\mathrm{O}_{2}$ should always be considered as a potential catalytic pathway.

As heterogeneous catalysis research moves forward to make significant advances and new scientific discoveries, we believe the following key questions related to the role of proton mobility during $\mathrm{O}_{2}$ activation should be addressed. For oxide supported metal catalysts, the local water structure and proton transfer at the three-phase boundary between the oxide, metal and fluid phase must be carefully characterized. Concomitantly, a predictive method for the amount and type of oxygen intermediates formed on the metal and the support as function of reaction conditions must be developed. This concept should then be expanded by considering a broader class of proton sources and shuttles, for example, alcohols or carboxylic acids. Finally, a better mechanistic understanding of which oxygen species participate in desired and undesired 
oxidation pathways is required to improve selectivity and atom-efficiency. Besides catalytic oxidation reactions, water-mediated proton transfer has other far-reaching implications, for instance, in catalytic hydrodeoxygenation of bio-oil [72], electrocatalysis [73-75], and any reaction using solid acid catalysts including zeolites [76,77]. Thus, we seenumerous opportunities for innovative research on water-assisted catalysis in diverse areas that may ultimately lead to disruptive technologies.

\section{Acknowledgements}

We gratefully acknowledge the National Science Foundation for financial support under award numbers $1465184,1258688,1160217$, and 1300619.

\section{References and recommended reading}

Papers of particular interest, published within the period of review, have been highlighted as:

- $\quad$ of special interest

$\bullet \quad$ of outstanding interest

[1] Ribe S, Wipf P: Water-accelerated organic transformations. Chem. Commun. 2001, 299-307.

[2] Goldsmith BR, Hwang T, Seritan S, Peters B, Scott SL: Rate-enhancing roles of water molecules in methyltrioxorhenium-catalyzed olefin epoxidation by hydrogen peroxide. J. Am. Chem. Soc. 2015, 137:9604-9616.

[3] Mullen GM, Gong J, Yan T, Pan M, Mullins CB: The Effects of Adsorbed Water on Gold Catalysis and Surface Chemistry. Top. Catal. 2013, 56:1499-1511.

This article reviews the surface chemistry of water on gold catalysts and its implications for $\mathrm{CO}$ oxidation. It concludes that the study of $\mathrm{O}_{2}$ activation on gold is a high priority research target.

[4] Fujitani T, Nakamura I, Haruta M: Role of water in CO oxidation on gold catalysts. Catal. Letters 2014, 144:1475-1486.

The authors have reviewed possible roles of water during CO oxidation over gold catalysts and logically group these roles into four main categories.

[5] Davies PR: On the Role of Water in Heterogeneous Catalysis: A Tribute to Professor M. Wyn Roberts. Top. Catal. 2016, 59:671-677.

This article highlights that beneficial effects of water as co-catalyst are not restricted to gold surfaces and are relevant for a wide variety of transition metals.

[6] Grotthuss CJT: Sur la décomposition de l'eau et des corps qu'elle tient en dissolution à l'aide de l'électricité galvanique. Ann. Chim. 1806, 58:54-74.

[7] Cukierman S: Et tu, Grotthuss! and other unfinished stories. Biochim. Biophys. Acta - 
Bioenerg. 2006, 1757:876-885.

[8]• Merte LR, Peng G, Bechstein R, Rieboldt F, Farberow CA, Grabow LC, Kudernatsch W, Wendt S, Laegsgaard E, Mavrikakis M, et al.: Water-Mediated Proton Hopping on an Iron Oxide Surface. Science 2012, 336:889-893.

High resolution and high speed scanning tunneling microscopy combined with density functional theory calculations provide strong evidence for a water-mediated proton transport mechanism across a well-defined iron-oxide surface.

[9] Farnesi Camellone M, Ribeiro Negreiros F, Szabova L, Tateyama Y, Fabris S: Catalytic Proton Dynamics at the Water/solid Interface of Ceria-supported Pt Clusters. J. Am. Chem. Soc. 2016, doi:10.1021/jacs.6b03446.

[10] Guo Z, Liu B, Zhang Q, Deng W, Wang Y, Yang Y: Recent advances in heterogeneous selective oxidation catalysis for sustainable chemistry. Chem. Soc. Rev. 2014, 43:3480-3524.

[11] Zhu Q, Wegener SL, Xie C, Uche O, Neurock M, Marks TJ: Sulfur as a selective "soft" oxidant for catalytic methane conversion probed by experiment and theory. Nat. Chem. 2013, 5:104-9.

[12] Peter M, Marks TJ: Platinum Metal-Free Catalysts for Selective Soft Oxidative Methane $\rightarrow$ Ethylene Coupling. Scope and Mechanistic Observations. J. Am. Chem. Soc. 2015, 137:15234-15240.

[13] Campos-Martin JM, Blanco-Brieva G, Fierro JLG: Hydrogen peroxide synthesis: An outlook beyond the anthraquinone process. Angew. Chemie - Int. Ed. 2006, 45:69626984.

[14] Grabow LC, Hvolbæk B, Falsig H, Nørskov JK: Search Directions for Direct H2O2 Synthesis Catalysts Starting from Au12 Nanoclusters. Top. Catal. 2012, 55:336-344.

[15]••Wilson NM, Flaherty DW: Mechanism for the Direct Synthesis of $\mathbf{H 2 O 2}$ on Pd Clusters: Heterolytic Reaction Pathways at the Liquid-Solid Interface. J. Am. Chem. Soc. 2016, 138:574-586.

This study simultaneously probes the effects of $\mathrm{Pd}$ cluster size and solvent $\mathrm{pH}$ for direct $\mathrm{H}_{2} \mathrm{O}_{2}$ synthesis. Kinetic interpretations of the obtained rate and selectivity data allows the authors to propose the first self-consistent reaction mechanism offering a unifying explanation of previously disparate reports.

[16]••Saavedra J, Doan HA, Pursell CJ, Grabow LC, Chandler BD: The critical role of water at the gold-titania interface in catalytic CO oxidation. Science 2014, 345:1599-1602.

For the first time, a kinetic H/D isotope effect has been observed, which provides unambiguous evidence for the importance of proton transfer steps during $\mathrm{CO}$ oxidation on gold. The results are incorporated into a unified mechanism of water enhanced $\mathrm{CO}$ oxidation with the clearly defined roles of water, support hydroxyl groups, and the goldtitania interface.

[17]••Saavedra J, Whittaker T, Chen Z, Pursell CJ, Rioux RM, Chandler BD: Controlling activity and selectivity using water in the Au-catalysed preferential oxidation of $\mathrm{CO}$ 
in H2. Nat. Chem. 2016, 8:584-589.

This work is an exemplary demonstration of using fundamental mechanistic insight of water-mediated $\mathrm{O}_{2}$ activation for the design of an industrially relevant process. Notably, using a commercial $\mathrm{Au} / \mathrm{Al}_{2} \mathrm{O}_{3}$ catalyst, record breaking $\mathrm{CO}$ conversion and $\mathrm{O}_{2}$ selectivity during the preferential oxidation of $\mathrm{CO}$ were achieved by tuning the surface water content.

[18] Sheu WS, Chang MW: CO oxidation on Ag(111): The catalytic role of H2O. Surf. Sci. 2014, 628:104-110.

[19]••Liu J-C, Tang Y, Chang C-R, Wang Y-G, Li J: Mechanistic Insights into Propene Epoxidation with $\mathrm{O} 2-\mathrm{H} 2 \mathrm{O}$ Mixture on Au7/a-Al203: A Hydroproxyl Pathway from ab Initio Molecular Dynamics Simulations. ACS Catal. 2016, 6:2525-2535.

The mechanism for propylene epoxidation with $\mathrm{O}_{2}-\mathrm{H}_{2} \mathrm{O}$ mixture over $\mathrm{Au}_{7} / \alpha-\mathrm{Al}_{2} \mathrm{O}_{3}$ catalyst was studied with computational methods that push the current state-of-the-art. The methods enable an assessment of water's role in altering the cluster shape as well as its direct participation in $\mathrm{O}_{2}$ activation.

[20]• Zope BN, Hibbitts DD, Neurock M, Davis RJ: Reactivity of the gold/water interface during selective oxidation catalysis. Science 2010, 330:74-78.

The mechanism of aerobic selective oxidation of alcohols to acids over various supported gold, palladium and platinum catalysts is reported. The role of water is to maintain adequate hydroxyl coverage and hydroxide ion concentration in solution, while $\mathrm{O}_{2}$ is needed to restore the hydroxyl/hydroxide consumed in selective alcohol oxidation.

[21]• Hammond C, Forde MM, Ab Rahim MH, Thetford A, He Q, Jenkins RL, Dimitratos N, Lopez-Sanchez JA, Dummer NF, Murphy DM, et al.: Direct catalytic conversion of methane to methanol in an aqueous medium by using copper-promoted Fe-ZSM-5. Angew. Chemie - Int. Ed. 2012, 51:5129-5133.

In an approach to mimick nature, the authors prepared a series of Cu-promoted Fe-ZSM5 catalysts samples. Using $\mathrm{H}_{2} \mathrm{O}_{2}$ as oxidant these catalysts were able to upgrade methane to methanol with three orders of magnitude higher ativity than previous studies.

[22]••Ojeda M, Zhan BZ, Iglesia E: Mechanistic interpretation of CO oxidation turnover rates on supported Au clusters. J. Catal. 2012, 285:92-102.

The beautiful kinetic experiments of this study are designed to elucidate the role of water during $\mathrm{CO}$ oxidation over supported gold and platinum catalysts. Water is shown to enhance $\mathrm{O}_{2}$ activation not only for gold, but also on platinum where $\mathrm{O}_{2}$ activation is hindered by $\mathrm{CO}$ poisoning. At high pressures the rate inhibition effect of water is explained by competitive adsorption and site blocking.

[23]••Yumura T, Hirose Y, Wakasugi T, Kuroda Y, Kobayashi H: Roles of Water Molecules in Modulating the Reactivity of Dioxygen-Bound Cu-ZSM-5 toward Methane: A Theoretical Prediction. ACS Catal. 2016, 6:2487-2495.

The first study to suggest that carefully controlled amounts of water can assist in the formation of radical oxygen containing active site motifs in Cu-ZSM-5 by proton transfer. These sites have predicted activity to selectively convert methane to methanol. 
[24] Dix ST, Scott JK, Getman RB, Campbell CT: Using degrees of rate control to improve selective n-butane oxidation over model MOF-encapsulated catalysts: stericallyconstrained Ag 3 Pd(111). Faraday Discuss. 2016, 188:21-38.

[25]••Perez Ferrandez DM, Herguedas Fernandez I, Teley MPG, de Croon MHJM, Schouten JC, Nijhuis TA: Kinetic study of the selective oxidation of propene with $\mathrm{O} 2$ over AuTi catalysts in the presence of water. J. Catal. 2015, 330:396-405.

Based on rate measurements and microkinetic modeling the oxygen species responsible for selective epoxidation of propylene and the unselective formation of acrolein $/ \mathrm{CO}_{2}$ were identified as $\mathrm{Au}-\mathrm{OOH}$ and $\mathrm{Au}-\mathrm{O}$, respectively.

[26] Taylor CD, Neurock M: Theoretical insights into the structure and reactivity of the aqueous/metal interface. Curr. Opin. Solid State Mater. Sci. 2005, 9:49-65.

[27] Ertl G: Reactions at surfaces: From atoms to complexity (nobel lecture). Angew. Chemie - Int. Ed. 2008, 47:3524-3535.

[28] Freund HJ, Meijer G, Scheffler M, Schlögl R, Wolf M: CO oxidation as a prototypical reaction for heterogeneous processes. Angew. Chemie - Int. Ed. 2011, 50:1006410094.

[29] Manasilp A, Gulari E: Selective CO oxidation over Pt/alumina catalysts for fuel cell applications. Appl. Catal. B Environ. 2002, 37:17-25.

[30] Sanchez-Castillo MA, Couto C, Kim WB, Dumesic JA: Gold-nanotube membranes for the oxidation of $\mathrm{CO}$ at gas-water interfaces. Angew. Chemie - Int. Ed. 2004, 43:11401142.

[31] Min BK, Friend CM: Heterogeneous gold-based catalysis for green chemistry: Lowtemperature CO oxidation and propene oxidation. Chem. Rev. 2007, 107:2709-2724.

[32] Gao F, McClure SM, Cai Y, Gath KK, Wang Y, Chen MS, Guo QL, Goodman DW: CO oxidation trends on Pt-group metals from ultrahigh vacuum to near atmospheric pressures: A combined in situ PM-IRAS and reaction kinetics study. Surf. Sci. 2009, 603:65-70.

[33] Haruta M, Kobayashi T, Sano H, Yamada N: Novel gold catalysts for the oxidation of carbon monoxide at a temperature far below $0^{\circ} \mathrm{C}$. Chem. Lett. 1987, doi:10.1246/cl.1987.405.

[34] Okumura M, Fujitani T, Huang J, Ishida T: A Career in Catalysis: Masatake Haruta. ACS Catal. 2015, 5:4699-4707.

[35] Bond GC, Thompson DT: Catalysis by Gold. Catal. Rev. 1999, 41:319-388.

[36] Hashmi ASK, Hutchings GJ: Gold Catalysis. Angew. Chemie Int. Ed. 2006, 45:78967936.

[37] Pina C Della, Falletta E, Rossi M: Update on selective oxidation using gold. Chem. Soc. Rev. 2012, 41:350-369.

[38] Dimitratos N, Hammond C, Kiely CJ, Hutchings GJ: Catalysis using colloidalsupported gold-based nanoparticles. Appl. Petrochemical Res. 2014, 4:85-94. 
[39] Bond GC, Thompson DT: Gold-Catalysed Oxidation of carbon monoxide. Gold Bull. 2000, 33:41-50.

[40] Date M, Okumura M, Tsubota S, Haruta M: Vital role of moisture in the catalytic activity of supported gold nanoparticles. Angew. Chemie - Int. Ed. 2004, 43:21292132.

[41] Daniells ST, Makkee M, Moulijn JA: The effect of high-temperature pre-treatment and water on the low temperature $\mathrm{CO}$ oxidation with Au/Fe2O3 catalysts. Catal. Letters 2005, 100:39-47.

[42] Calla JT, Davis RJ: Oxygen-exchange reactions during CO oxidation over titaniaand alumina-supported Au nanoparticles. J. Catal. 2006, 241:407-416.

[43] Bongiorno A, Landman U: Water-enhanced catalysis of $\mathrm{CO}$ oxidation on free and supported gold nanoclusters. Phys. Rev. Lett. 2005, 95:106102.

[44] Bergeld J, Kasemo B, Chakarov D: CO oxidation on Pt (111) promoted by coadsorbed H2O. Surf. Sci. 2001, 495:L815-L820.

[45] Huang J, Haruta M: Gas-phase propene epoxidation over coinage metal catalysts. Res. Chem. Intermed. 2012, 38:1-24.

[46] Linic S, Christopher P: Overcoming Limitation in the Design of Selective Solid Catalysts by Manipulating Shape and Size of Catalytic Particles: Epoxidation Reactions on Silver. ChemCatChem 2010, 2:1061-1063.

[47] Yang X, Kattel S, Xiong K, Mudiyanselage K, Rykov S, Senanayake SD, Rodriguez JA, Liu P, Stacchiola DJ, Chen JG: Direct Epoxidation of Propylene over Stabilized Cu+ Surface Sites on Titanium-Modified Cu2O. Angew. Chemie - Int. Ed. 2015, 54:1194611951.

[48] Prieto G, Schüth F: The Yin and Yang in the development of catalytic processes: Catalysis research and reaction engineering. Angew. Chemie - Int. Ed. 2015, 54:3222-3239.

[49] Hayashi T, Tanaka K, Haruta M: Selective Vapor-Phase Epoxidation of Propylene over Au/TiO2Catalysts in the Presence of Oxygen and Hydrogen. J. Catal. 1998, 178:566-575.

[50] Ojeda M, Iglesia E: Catalytic epoxidation of propene with $\mathrm{H} 2 \mathrm{O}-\mathrm{O} 2$ reactants on Au/TiO 2. Chem. Commun. 2009, 2:352-354.

[51] Huang J, Akita T, Faye J, Fujitani T, Takei T, Haruta M: Propene epoxidation with dioxygen catalyzed by gold clusters. Angew. Chemie - Int. Ed. 2009, 48:7862-7866.

[52] Lee S, Molina LM, López MJ, Alonso JA, Hammer B, Lee B, Seifert S, Winans RE, Elam JW, Pellin MJ, et al.: Selective propene epoxidation on immobilized Au6-10 clusters: The effect of hydrogen and water on activity and selectivity. Angew. Chemie - Int. Ed. 2009, 48:1467-1471.

[53] Huang J, Takei T, Ohashi H, Haruta M: Propene epoxidation with oxygen over gold clusters: Role of basic salts and hydroxides of alkalis. Appl. Catal. A Gen. 2012, 435436:115-122. 
[54] Chang CR, Wang YG, Li J: Theoretical investigations of the catalytic role of water in propene epoxidation on gold nanoclusters: A hydroperoxyl-mediated pathway. Nano Res. 2011, 4:131-142.

[55] Mallat T, Baiker A: Oxidation of alcohols with molecular oxygen on solid catalysts. Chem. Rev. 2004, 104:3037-3058.

[56] Villa A, Dimitratos N, Chan-Thaw CE, Hammond C, Prati L, Hutchings GJ: Glycerol oxidation using gold-containing catalysts. Acc. Chem. Res. 2015, 48:1403-1412.

[57] Freakley SJ, He Q, Kiely CJ, Hutchings GJ: Gold Catalysis: A Reflection on Where We are Now. Catal. Letters 2015, 145:71-79.

[58] Xu B, Liu X, Haubrich J, Friend CM: Vapour-phase gold-surface-mediated coupling of aldehydes with methanol. Nat. Chem. 2010, 2:61-65.

[59] Abad A, Concepción P, Corma A, García H: A collaborative effect between gold and a support induces the selective oxidation of alcohols. Angew. Chemie - Int. Ed. 2005, 44:4066-4069.

[60] Griffin MB, Rodriguez AA, Montemore MM, Monnier JR, Williams CT, Medlin JW: The selective oxidation of ethylene glycol and 1,2-propanediol on $\mathrm{Au}, \mathrm{Pd}$, and $\mathrm{Au}-\mathrm{Pd}$ bimetallic catalysts. J. Catal. 2013, 307:111-120.

[61] Ketchie WC, Fang YL, Wong MS, Murayama M, Davis RJ: Influence of gold particle size on the aqueous-phase oxidation of carbon monoxide and glycerol. J. Catal. 2007, 250:94-101.

[62] Ketchie WC, Murayama M, Davis RJ: Selective oxidation of glycerol over carbonsupported AuPd catalysts. J. Catal. 2007, 250:264-273.

[63] Chang CR, Yang XF, Long B, Li J: A water-promoted mechanism of alcohol oxidation on a Au(111) surface: Understanding the catalytic behavior of bulk gold. ACS Catal. 2013, 3:1693-1699.

[64] Hammond C, Conrad S, Hermans I: Oxidative Methane Upgrading. ChemSusChem 2012, 5:1668-1686.

[65] Olivos Suarez Al, Szécsényi Á, Hensen EJM, Ruiz-Martínez J, Pidko EA, Gascon J: Strategies for the direct catalytic valorization of methane using heterogeneous catalysis: challenges and opportunities. ACS Catal. 2016, 6:2965-2981.

[66] Sheppard T, Daly H, Goguet A, Thompson JM: Improved Efficiency for Partial Oxidation of Methane by Controlled Copper Deposition on Surface-Modified ZSM-5. ChemCatChem 2015, 8:562-570.

[67] Forde MM, Armstrong RD, Hammond C, He Q, Jenkins RL, Kondrat SA, Dimitratos N, Lopez-Sanchez JA, Taylor SH, Willock D, et al.: Partial Oxidation of Ethane to Oxygenates Using Fe- and Cu-Containing ZSM-5. J. Am. Chem. Soc. 2013, 135:11087-11099.

[68] Woertink JS, Smeets PJ, Groothaert MH, Vance MA, Sels BF, Schoonheydt RA, Solomon El: A [Cu2O]2+ core in Cu-ZSM-5, the active site in the oxidation of methane to methanol. Proc. Natl. Acad. Sci. U. S. A. 2009, 106:18908-18913. 
[69] Grundner S, Markovits MAC, Li G, Tromp M, Pidko EA, Hensen EJM, Jentys A, SanchezSanchez M, Lercher JA: Single-site trinuclear copper oxygen clusters in mordenite for selective conversion of methane to methanol. Nat. Commun. 2015, 6:7546.

[70] Zhao Z-J, Kulkarni A, Vilella L, Nørskov JK, Studt F: Theoretical Insights into the Selective Oxidation of Methane to Methanol in Copper-Exchanged Mordenite. ACS Catal. 2016, 6:3760-3766.

[71] Gao D, Wang S, Zhang C, Yuan Z, Wang S: Methane Combustion over Pd/Al2O3 Catalyst: Effects of Chlorine Ions and Water on Catalytic Activity. Chinese J. Catal. 2008, 29:1221-1225.

[72] Nelson RC, Baek B, Ruiz P, Goundie B, Brooks A, Wheeler MC, Frederick BG, Grabow LC, Austin RN: Experimental and Theoretical Insights into the Hydrogen-Efficient Direct Hydrodeoxygenation Mechanism of Phenol over Ru/TiO2. ACS Catal. 2015, 5:6509-6523.

[73] Zhu W, Michalsky R, Metin Ö, Lv H, Guo S, Wright CJ, Sun X, Peterson A a, Sun S: Monodisperse Au Nanoparticles for Selective Electrocatalytic Reduction of CO2 to CO Monodisperse Au Nanoparticles for Selective Electrocatalytic Reduction of CO 2 to CO. J Amer Chem Soc 2013, 420:2-5.

[74] Zhu W, Zhang Y-J, Zhang H, Lv H, Li Q, Michalsky R, Peterson AA, Sun S: Active and Selective Conversion of $\mathbf{C O}_{2}$ to $\mathbf{C O}$ on Ultrathin Au Nanowires. J. Am. Chem. Soc. 2014, 136:16132-16135.

[75] Nie X, Esopi MR, Janik MJ, Asthagiri A: Selectivity of CO2 Reduction on Copper Electrodes: The Role of the Kinetics of Elementary Steps. Angew. Chemie Int. Ed. 2013, 52:2459-2462.

[76] Copeland JR, Shi X-R, Sholl DS, Carsten Sievers: Surface Interactions of C2 and C3 Polyols with Y-Al2O3 and the Role of Coadsorbed Water. Langmuir 2013, 29:581593.

[77] Molinari JE, Nakka L, Kim T, Wachs IE: Dynamic Surface Structures and Reactivity of Vanadium-Containing Molybdophosphoric Acid (H3+xPMo12-xVxO40) Keggin Catalysts during Methanol Oxidation and Dehydration. ACS Catal. 2011, 1:15361548. 
Graphical Abstract

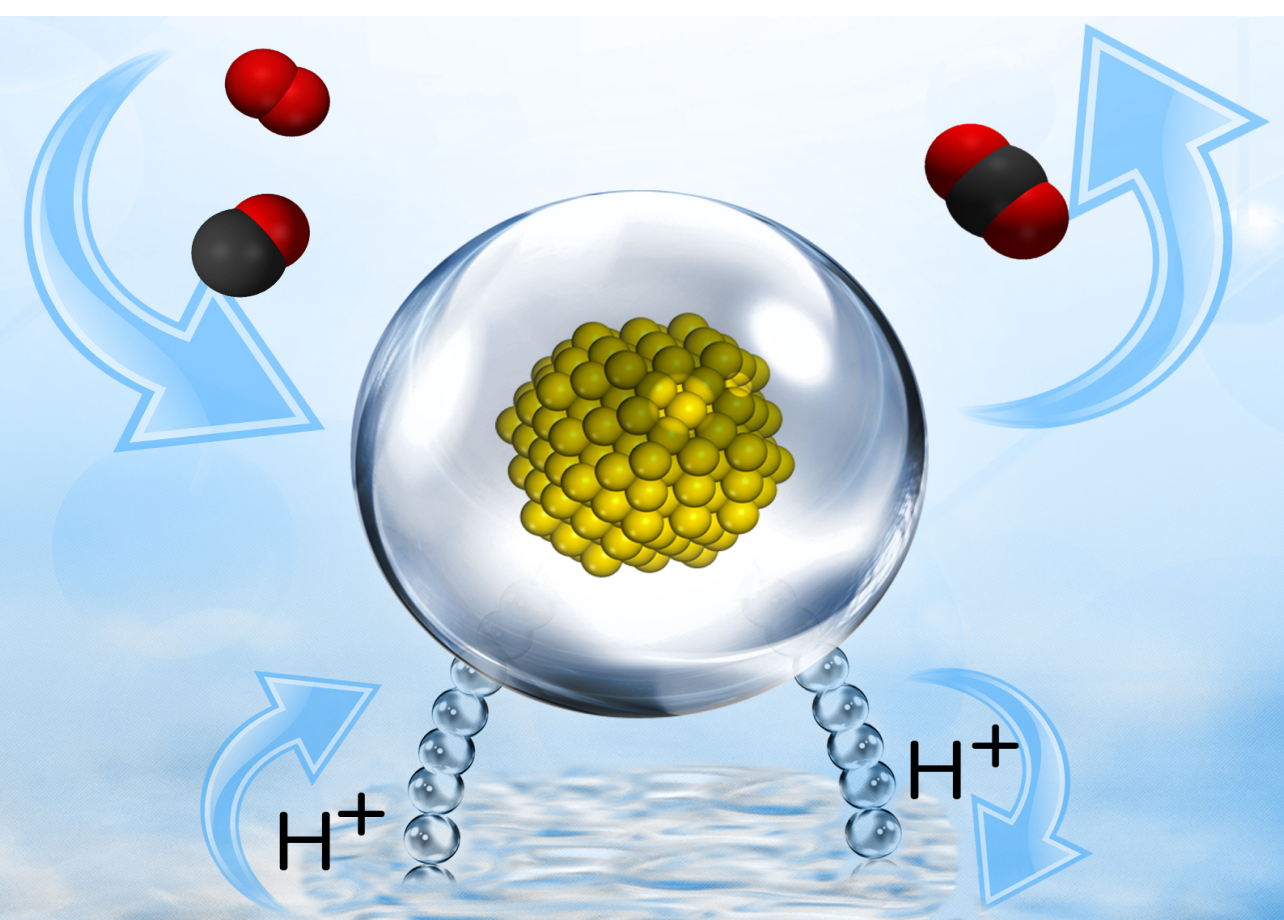

